\title{
Lifetime Modeling of LED luminaires by Dual-stress Accelerated Life
}

\author{
Test \\ Huajing $\mathrm{Li}^{1, \mathrm{a}^{*}}$, Lei $\mathrm{Nie}^{1,2,3, \mathrm{~b}^{*}}$, and Fei Huang ${ }^{1, \mathrm{c}}$ \\ ${ }^{1}$ School of Mechanical Engineering, Hubei University of Technology, \\ Wuhan, 430068, P. R. China \\ ${ }^{2}$ Key Lab of Modern Manufacture Quality Engineering, Hubei University of Technology, Wuhan, \\ 430068, P. R. China \\ ${ }^{3}$ State Key Lab of Digital Manufacturing Equipment and Technology, Huazhong University of \\ Science and Technology, Wuhan, P. R. China \\ a'Li_huajing@foxmail.com, b leinie@hbut.edu.cn, c $349029353 @ q q . c o m$
}

Keywords: LED luminaires, lifetime, Dual-stress accelerate test, modeling, variance analysis

Abstract. LED luminaires, the research object, is the new energy industry products. And aiming at the lifetime prediction and reliability evaluation of LED luminaires, a novel dual-stress accelerated life tests were designed and lifetime models were developed. The temperature and vibration were selected as the test stresses and loaded on the test samples simultaneous. According to the experimental results, life curve of LED luminaires obey to exponential model and the method can assess the reliability, quickly and effectively. The precision and accuracy of lifetime model was validated by means of variance analysis.

\section{Introduction}

Semiconductor light-emitting diode (LED), as the mainstay of the new energy industry, is characterized by small volume, long lifetime and high efficiency. Owing to those properties of new energy and industry, its application fields extend greatly ${ }^{[1-3]}$. However, there is often a huge gap between the working time of LED luminaires and the theoretical life because of lacking effective reliability test. Many time consuming and high-cost traditional standards and reliability tests are still conducted to assess the reliability of LED luminaries. Therefore, innovation and reconstruction of reliability tests for LED luminaries are pivotal problem which is being demanded prompt solution.

Actually, life test is still an common method to assess the reliability of new energy industry products, especially for semiconductor light-emitting products. However, due to the complex structure and long life expectancy (about 25,000 hours theoretically), LED's life test under normal stress would last for a long time, and the accuracy and reliability of this prediction is hard to be obtained ${ }^{[4]}$. According to the Arrhenius model, the lifetime was inversely proportional to the temperature. In order to shorten the test time, accelerated life test (ALT) is developed in which higher stress level is applied and better test efficiency can be achieved. Therefore, ALT is a powerful method to acquire the data of lifetime and assess the reliability of the LED luminaires. In fact, using ALT to research the reliability of LED has become a hot topic nowadays ${ }^{[5-7]}$.

Three failure modes of LED luminaires were put forward by X. P. Li and L. Chen ${ }^{[8]}$. Trevisanello researched mechanism of LED luminaires thought ALT. The results shown that the 
samples' failures were caused by epoxy resin browning with the temperature rising ${ }^{[9]}$. M. Cai and D. G. Yang analyzed the failure modes and conducted the life extrapolation of LED luminaires by single-stress ALT ${ }^{[10]}$. These results suggested that the lifetime of LED luminaires was associated with many factors. And only under different experimental conditions can sample completely exposed its failure modes and accelerated aging samples. Therefore, the different stresses should be applied at the same time during the ALT when the lifetime of LED luminaires was predicted.

A novel test method of dual-stress (temperature and vibration) ALT was applied to accelerate the test process and reduce the energy loss. The life time of LED luminaires was predicted by the method of least square and simple linear regression based on the test data. In order to verify the accuracy of the life model, regression treatment of analysis of variance was used to verify the accuracy and veracity of the test data and life model. The lifetime model including reasonable mathematical expressions were derived to predict the LED lifetime. The quick prediction and reliability assessment can be achieved based on this model.

\section{Experiment}

\section{Test design.}

The appropriate temperature and vibration stresses level were determined according to the results of exploratory test. Then, the vibration stresses of accelerated life test were combined to establish final dual-stress accelerate life test. This kind of method was quicker and cheaper than traditional life test, which was usually impractical because lifetime was so long ${ }^{[11-12]}$. In order to find out the reasonable experimental factors, The orthogonal design and analysis method were conducted. The flow diagram of the test was shown in Fig.1.

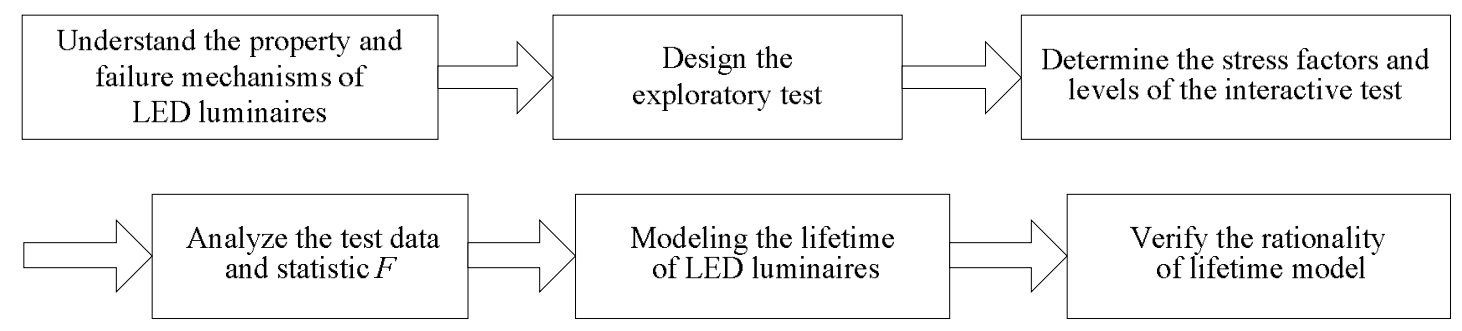

Fig. 1 The flow diagram of the test

\section{Sample and equipment.}

The experimental samples were 6.5w white LED luminaires numbered CJ-BB03A, showed in Fig.2 (left). The preprocessed sample was shown in Fig.2 (right). The samples were encapsulated by SMD (surface mount device) and substrate material were aluminum. In order to ensure the reliability of data, the samples were fabricated with the same sapphire substrate and chose from the same manufacturer.

Fig. 3 showed the test clamp which can fix the samples on vibration table and transmit vibration effectively. QualMark vibration testing (HALT/HASS) chamber was utilized to conduct an interactive accelerate test, shown in Fig.4. Its controllable temperature and vibration range are $-100^{\circ} \mathrm{C} \sim+200^{\circ} \mathrm{C}$ and $0 \sim 60 \mathrm{~g}$, respectively. 


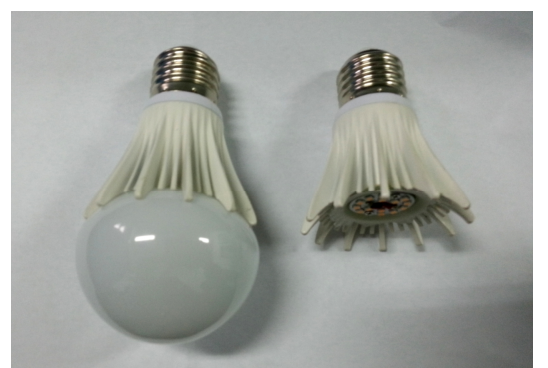

Fig.2 Test Sample

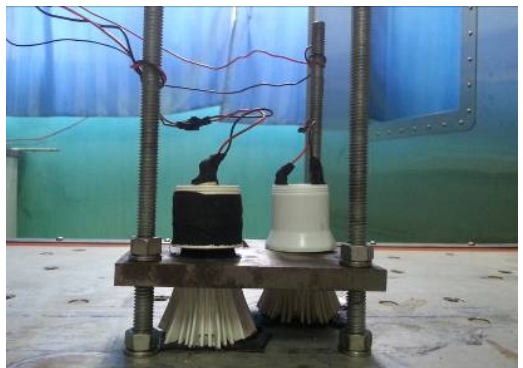

Fig.3 Test Clamp

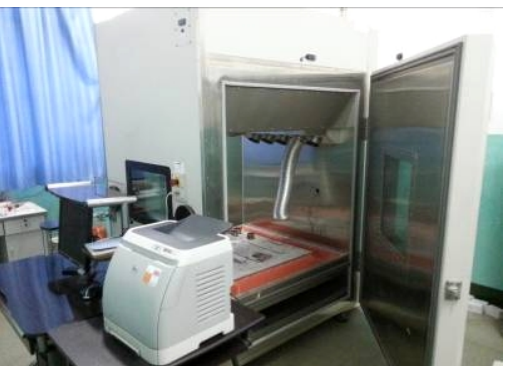

Fig.4 QualMark vibration testing (HALT/HASS ) chamber

\section{Results of Exploratory test}

The structure of LED luminaires consisted of LED models, drive system, radiator and extra mechanical structures. There are many different kinds of failure modes and mechanisms during the period of the experiment ${ }^{[13]}$. Thus, the reasonable test stresses were significant.

Throughout the exploratory test process, the intent was to determine its operating limits and accurate accelerate stress. Base on the exploratory test data, the interactive test included two factors: temperature and vibration. And the temperature and vibration stress were set from $140^{\circ} \mathrm{C}$ to $180^{\circ} \mathrm{C}$ and $20 \mathrm{~g}$ to $40 \mathrm{~g}$, respectively. The step size of temperature was $10^{\circ} \mathrm{C}$ and vibration was $10 \mathrm{~g}$. In order to ensure the rationality of life test , 5 samples were used in each group.

\section{Data Analysis}

The average lifetime of samples were showed in Table 1 According to the Table 1, the variation of lifetime and temperature has been fitted as show in Fig.5.

Table. 1 Test Data

\begin{tabular}{|c|c|c|c|}
\hline \multicolumn{2}{|c|}{ Vibration stress $(\mathrm{g})$} & & \\
\hline Average lifetime(s) & $40 \mathrm{~g}$ & $30 \mathrm{~g}$ & $20 \mathrm{~g}$ \\
\hline $180^{\circ} \mathrm{C}$ & 54.8 & 123 & 260.5 \\
\hline $170^{\circ} \mathrm{C}$ & 196.4 & 261.2 & 323.5 \\
\hline $160^{\circ} \mathrm{C}$ & 438.2 & 510.5 & 556.8 \\
\hline $150^{\circ} \mathrm{C}$ & 682.5 & 685.5 & 968.5 \\
\hline $140^{\circ} \mathrm{C}$ & 1756.8 & 1763.8 & 1883 \\
\hline
\end{tabular}

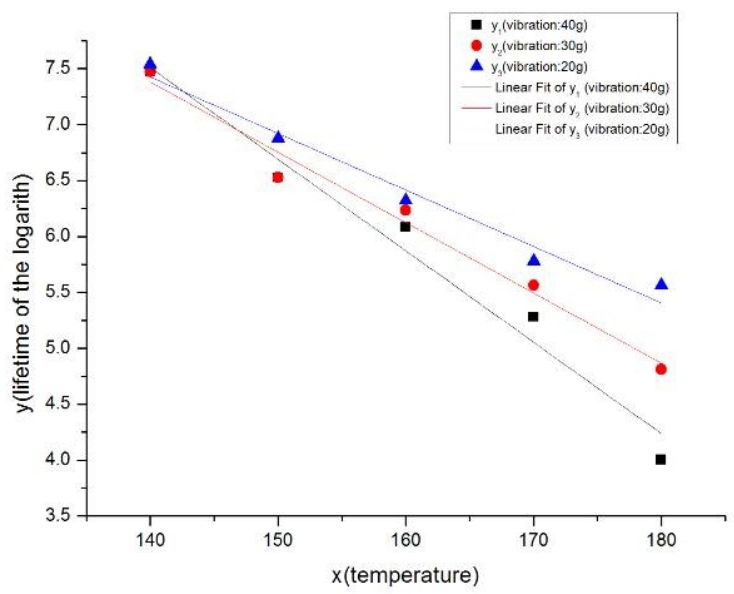

Fig.5 temperature - life fitting result 
Abscissa $\mathrm{x}$ represents temperature and ordinate $\mathrm{y}$ represents the lifetime of the logarithm. In order to validate the accuracy of fitting formula and lifetime model, the significance analysis was performed based on the result of ALT.

The Correlation coefficient $\gamma$ and statistic $\mathrm{F}$ under different condition were shown in Table 2 . (Condition 1:Vibration stress:40g,Temperature stress : $140^{\circ} \mathrm{C}-180^{\circ} \mathrm{C}$; Condition 2:Vibration stress:30g, Temperature stress: $140^{\circ} \mathrm{C}-180^{\circ} \mathrm{C}$; Condition 3:Vibration stress:20g, Temperature stress: $140^{\circ} \mathrm{C}-180^{\circ} \mathrm{C}$ ) Based on the SPSS analysis data in Table 2. The correlation coefficients of three levels were all close to 1 , which meant the variations are significant correlation in 0.01 level. Thus, the linear relation between $\mathrm{x}$ and $\mathrm{y}$ was excellent and the liner functional of equation $(\mathrm{y}=\mathrm{a}+\mathrm{bx})$ was correct. All values of statistic F were larger than standard value F0.01(1,3)=34.12. Therefore, the effect of environmental stress was remarkable. The test of significance showed that fitting results were in good agreement with the experiments.

Table. 2 The results of SPSS analysis

\begin{tabular}{|c|c|c|c|c|}
\hline $\begin{array}{c}\text { Environmental } \\
\text { stress }\end{array}$ & $\begin{array}{c}\text { Degraded } \\
\text { path model }\end{array}$ & $\begin{array}{c}\text { Correlation } \\
\text { coefficient } \gamma\end{array}$ & Statistic F & $R^{2}$ \\
\hline \multirow{2}{*}{ Condition 1 } & \multirow{2}{*}{$\mathrm{y}=\mathrm{a}+\mathrm{bx}$} & $-0.987^{* *}$ & 112.893 & 0.974 \\
\cline { 1 - 3 } Condition 2 & $-0.990^{* *}$ & 151.015 & 0.981 \\
\cline { 4 - 5 } Condition 3 & & $-0.987^{* *}$ & 116.250 & 0.975 \\
\hline
\end{tabular}

The correlation coefficient $\mathrm{R}$ and statistic $\mathrm{F}$ showed that temperature was closely related to lifetime of the LED luminaires. On this basis, the life distribution of the LED luminaires obeyed exponential distribution and fitting formulas were shown in Table 3.

Table.3 Fitting Formulas

\begin{tabular}{|c|c|}
\hline Environmental Stress & Fitting Formulas \\
\hline Condition 1 & $\mathrm{y} 1=-0.0818 \mathrm{x}+18.962$ \\
\hline Condition 2 & $\mathrm{y} 2=-0.0629 \mathrm{x}+16.189$ \\
\hline Condition 3 & $\mathrm{y} 3=-0.0505 \mathrm{x}+14.500$ \\
\hline
\end{tabular}

\section{Results and Discussion}

The results indicated that the Dual-stress accelerated life test was a novel and efficient method for the modeling lifetime of LED luminaires. According to the testing data, the accelerated effect of test was very obvious under the condition of high stress. It can not only efficient, but also economical. The stresses of vibration and temperature both had impacts upon LED luminaires. The concrete analysis as following:

1. The traditional single-stress accelerated life was hard to simulate actual work of comprehensive environment. Based on the fitting formulas, the LED luminaires lifetime of extrapolation was almost $561013 \mathrm{~s}$ under the room temperature environment $\left(25^{\circ} \mathrm{C}\right)$. Thus, in order to enhance the experimental speed and improve the precision of the result, Dual-stress accelerated life test was used.

2. The influence of temperature on the LED luminaires was very significant. In the case of vibration stress of $40 \mathrm{~g}$, LED luminaires had the shortest lifetime at $180^{\circ} \mathrm{C}$. The life of the LED luminaires decreased with the increase of temperature. Part of the samples had visible carbonization in the silicone filler because of the high temperature. 
3. The lifetime decay curve of LED luminaires obeyed exponential distribution. The fitting formulas were calculated based on the experimental data. Vibration had some effect on LED luminaires. With the increase of temperature and vibration stress, the fitting formula of slope decreased gradually.

\section{Conclusions}

In order to develop the lifetime model of LED luminaires efficiently, Dual-stress ALT was used which applied temperature and vibration stresses in the same time. Based on the results of ALT, a lifetime prediction model was developed by the means of least square method. According to this model, lifetime of LED luminaires under different stress level can be deduced.

\section{Acknowledgments}

This work was funded by National Natural Science Foundation of China (50975106), the Natural Science Foundation of Hubei Province of China (2014CFB178), open foundation of State Key Lab of Digital Manufacturing Equipment \& Technology(DMETKF2014017), Educational Commission of Hubei Province of China(D20131407), and the State Key Laboratory of Silicate Materials for Architectures (Wuhan University of Technology, No: SYSJJ2013-10)

\section{References}

[1] Krames, M. R.,Philips Lumileds Lighting Co.and San Jose, CA at al, Status and Future of High-Power Light-Emitting Diodes for Solid-State Lighting ,Display Technology, Vol. 3, 165-175, 2007.

[2] W. D. van Driel et al, Solid State Lighting Reliability: From Components to System, ChinaSSL, 202-206, 2010.

[3] S. Liu and X. Luo, LED Packaging for Lighting Applications: Design, Manufacturing and Reliability, John Wiley and Sons,3-6, 2011.

[4] X. P. Li, L. Chen and M. Chen, An approach of LED lamp system lifetime prediction , ICQR, 110- 114, 2011.

[5] Y. S. wang, L. Y. zhang and S. J. Diao, Test and Analysis of High-Power LED Accelerated Life , China Academic Journal Electronic Publishing House, vol.34, 986-999, 2009.

[6] Nelson W B, Accelerated life testing-step-stress models and data analysis', IEEE Transactions on Reliability, vol.29,No.2,103-108, 1980.

[7] S. Ishizaki , H. Kimura and M. Sugimoto, Lifetime estimation of high power white LEDs, J. Light Visual Environment, vol. 31, No.1,11 -18, 2007.

[8] X. P. Li, L. Chen, M.Chen, An Approach of LED Lamp System Lifetime Prediction ,IEEE,2011.

[9] L. R Trevisanello et al, Accelerated life test of high brightness light emitting diodes, IEEE Trans-DMR,vol.8(2),304-311,2008.

[10] M. Cai, D. G. Yang and S. Koh , Accelerated Testing Method of LED Luminaries , EuroSimE, 2012.

[11] M. Cai, D. G. Yang and W. B. Chen et al, A reliability analysis method for LED luminaires based on step stress accelerated degradation test ,ICEPT, 1207 - 1211, 2013.

[12] Steinberg D S, Vibration analysis of electronic equipment ,USA:John Wiley\&sons, 1988. 
[13] Y. C. Liu, G. C. Fu and C. Gao et al, Thermal analysis of illumination high-power LED, Chinese Journal of Electron Devices, vol.31, 1716-1719, 2008. 